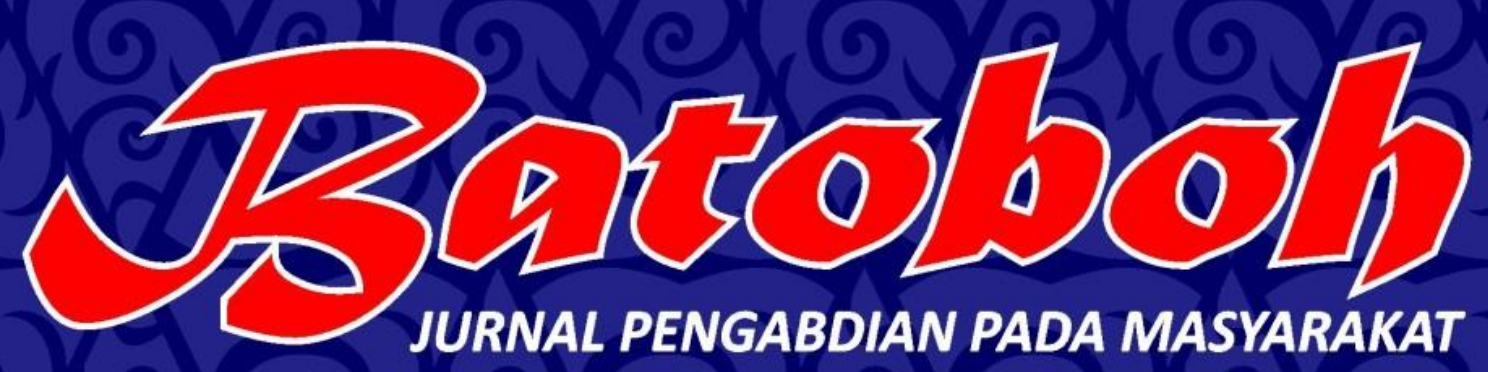

ISSN: 2548-5458

Volume 1

Nomor 2

JURNAL PENGABDIAN PADA MASYARAKAT

Oktober 2016

hlm. 131-266

Yusfil, Zulkifli, Erlinda

PENERAPAN TEKNOLOGI SENI PADA SANGGAR SENI TRADISIONAL

DI KABUPATEN PESISIR SELATAN SUMATERA BARAT

Asril

PELATIHAN LAGU SIONTONG TABANG, KURETA MANDAKI, DAN OYAK TABUIK

PADA GRUP GANDANG TASA ANAK-ANAK, SANGGAR ANAK NAGARI DESA SUNGAI PASAK, KOTA PARIAMAN

Nofrial, Wahyono, Riski Rahmat Kurniawan Dan Alek Hengki Ziora

PEMANFAATAN SERBUK GERGAJI MENJADI PRODUK KERAJINAN DI WAN PERABOT,

TARANTANG KECAMATAN HARAU, 50 KOTA

Dira Herawati, Muhammad Husni, A Nick Koto Agam, Eza Ramadhani

PELATIHAN FOTOGRAFI PADA KEGIATAN EKSTRA KURIKULER DI SMKN 2 PADANGPANJANG

F. X Yatno Karyadi, Eriswan, Bari, Rahmat, Irham

PELATIHAN PEMBUATAN VIDEO DAN FOTO MAKRO MENGGUNAKAN TABLE-TOP STUDIO UNTUK SISWA SMA

Novina Yetri Fatrina, Ediantes, Putri Andam Dewi, Suri Handai Yani

PELATIHAN TEKNIK MEMBUAT RIAS EFEK UNTUK FILM FIKSI PADA SMK 2 PADANGPANJANG

Rosta Minawati, Heri Sasongko, Gilang Febriano, Vini Rusmana

PENGENALAN PRODUKSI FILM DOKUMENTER BAGI SISWA/ SISWI SEKOLAH MENEGAH ATAS

Hafif HR, Fahmi Marh, Ade Sulistiawan, Dino Ashari

PENERAPAN MULTI DISIPLIN SENI DALAM KEGIATAN DRUMBAND PADA EKSTRAKURIKULER SMA 3 PADANGPANJANG

Febri Yulika, Selvi kasman, Putri Khairina Masta

PENINGKATAN KOMPETENSI GURU MELALUI PELATIHAN PENULISAN KARYA TULIS ILMIAH

Darmansyah, Novesar Jamarun, Firdaus, Indra Arifin, Fitra Muhaddis

PELATIHAN INSTRUMEN MUSIK TRADISIONAL MINANGKABAU DI MAN 2 GUNUNG PADANGPANJANG 



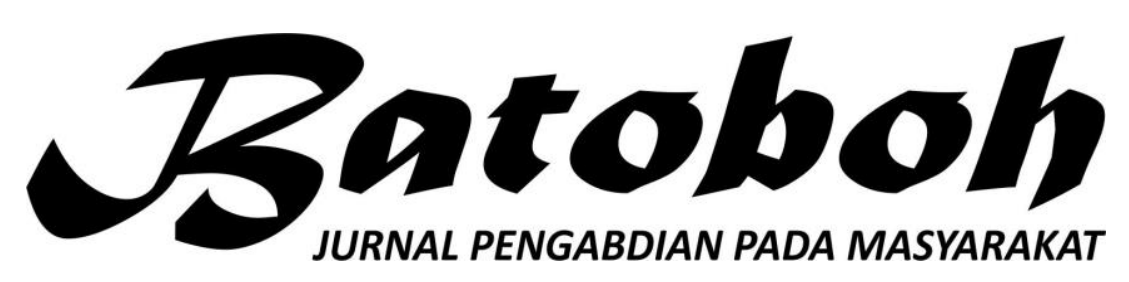

ISSN: 2548-5458 Volume 1, Nomor 2, Oktober 2016, hlm. 131-266

Terbit dua kali setahun pada bulan April dan Oktober. Pengelola Jumal Pengabdian pada Masyarakat merupakan subsistem LPPMPP Institut Seni Indonesia (ISI) Padangpanjang.

\author{
Pengarah \\ Rektor ISIPadangpanjang \\ Penanggung Jawab \\ Kepala Pusat Penerbitan ISI Padangpanjang \\ KetuaPenyunting \\ Andar Indra Sastra \\ Penyunting \\ Asril \\ Sahrul \\ RostaMinawati \\ Harissman \\ Pimpinan Redaksi \\ Saaduddin \\ Redaktur \\ Liza Asriana \\ Rori Dolayance \\ Tata Letak dan Desain Sampul \\ Yoni Sudiani \\ WebJurnal \\ Thegar Risky
}

Alamat Pengelola Jumal Batoboh:LPPMPP ISI Padangpanjang

Jalan Bahder Johan Padangpanjang 27128, Sumatera Barat; Telepon (0752) 82077 Fax. 82803;

e-mail; batoboh@gmail.com

Catatan. Isi/Materi jurnal adalah tanggung jawab Penulis.

Diterbitkan Oleh

Institut Seni Indonesia (ISI) Padangpanjang 


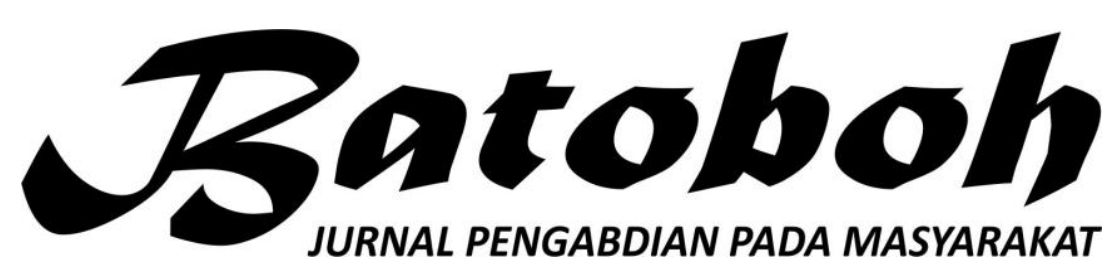

ISSN: 2548-5458 Volume 1, Nomor 2, Oktober 2016, hlm. 131-266

\section{DAFTAR ISI}

\begin{tabular}{|l|l|}
\hline \multicolumn{1}{|c|}{ PENULIS } & \multicolumn{1}{c}{ JUDUL } \\
\hline Yusfil, Zulkifli, Erlinda & $\begin{array}{l}\text { Penerapan Teknologi Seni Pada Sanggar Seni } \\
\text { Tradisional Di Kabupaten Pesisir Selatan Sumatera } \\
\text { Barat }\end{array}$ \\
Asril & $\begin{array}{l}\text { Pelatihan Lagu Siontong Tabang, Kureta Mandaki, } \\
\text { Dan Oyak Tabuik Pada Grup Gandang Tasa Anak- } \\
\text { Anak, Sanggar Anak Nagari Desa Sungai Pasak, } \\
\text { Kota Pariaman }\end{array}$ \\
$\begin{array}{l}\text { Nofrial, Wahyono, Riski } \\
\text { Rahmat Kurniawan Dan } \\
\text { Alek Hengki Ziora }\end{array}$ & $\begin{array}{l}\text { Pemanfaatan Serbuk Gergaji Menjadi Produk } \\
\text { Kerajinan Di Wan Perabot, Tarantang Kecamatan } \\
\text { Harau, 50 Kota }\end{array}$ \\
\hline
\end{tabular}

HALAMAN

Dira Herawati,

Muhammad Husni, A

Nick Koto Agam, Eza

Ramadhani

F. X Yatno Karyadi,

Pelatihan Fotografi Pada Kegiatan Ekstra

Kurikuler Di SMKN 2 Padangpanjang

131-144

$145-164$

Eriswan, Bari, Rahmat, Irham

Novina Yetri Fatrina, Ediantes, Putri Andam Dewi, Suri Handai Yani

Pelatihan Pembuatan Video Dan Foto Makro

190-200 Menggunakan Table-Top Studio Untuk Siswa SMA

Pelatihan Teknik Membuat Rias Efek Untuk Film 201-212 Fiksi Pada SMK 2 Padangpanjang

Rosta Minawati, Heri Sasongko, Gilang

Pengenalan Produksi Film Dokumenter Bagi $213-227$ Febriano, Vini Rusmana

Hafif HR, Fahmi Marh, Ade Sulistiawan, Dino Ashari Siswa/Siswi Sekolah Menegah Atas

$165-181$ 182-189

Febri Yulika, Selvi Kasman, Putri Khairina Masta

Darmansyah, Novesar Jamarun, Firdaus' Indra Arifin, Fitra Muhaddis

Penerapan Multi Disiplin Seni Dalam Kegiatan Drumband Pada Ekstrakurikuler SMA 3 Padangpanjang

Peningkatan Kompetensi Guru Melalui Pelatihan Penulisan Karya Tulis Ilmiah

Pelatihan Instrumen Musik Tradisional $256-266$ Minangkabau Di MAN 2 Gunung Padangpanjang

\footnotetext{
Peraturan Direktur Jenderal Pendidikan Tinggi Kementerian Pendidikan Kebudayaan Republik Indonesia Nomor 1 Tahun 2014 Tanggal Tentang Pedoman Akreditasi Terbitan Berkala Ilmiah. Jumal Batoboh Terbitan Vol. 1, April dan Oktober 2016 Memakaikan Pedoman Akreditasi Berkala Ilmiah Tersebut.
} 



\title{
PELATIHAN PEMBUATAN VIDEO DAN FOTO MAKRO MENGGUNAKAN TABLE-TOP STUDIO UNTUK SISWA SMA
}

\author{
F. X Yatno Karyadi, Eriswan, Bari, Rahmat, Irham \\ Prodi TV dan Film \\ Fakultas Seni Rupa dan Disain- ISI Padangpanjang. \\ Jl. Bahder Johan, Padangpanjang, Sumatra Barat \\ lagipanen@gmail.com
}

\begin{abstract}
ABSTRAK
Pelatihan pembuatan video dan foto makro menggunakan table-top studio untuk siswa SMA adalah bentuk program pelatihan pembuatan karya seni video dan foto, dengan peserta siswa sekolah menengah atas. Table top studio merupakan studio kecil yang digunakan untuk membuat kesan ruang tanpa batas pada objek karya video dan foto. Pelatihan bertujuan untuk meningkatkan rangsangan bagi siswa dalam memperkaya pengetahuan tentang jenis karya seni foto dan video. Meningkatkan pemahaman dan pengetahuan teknik dasar videografi atau fotografi. Pelatihan menggunakan metode workshop dengan praktik membuat karya video dan karya foto. Hasil yang diperoleh berupa karya video dan foto. Karya foto dicetak sebagai bahan untuk materi majalah dinding. Karya video dipersiapkan untuk mengisi konten pada media sosial dan video blog (vlog). Hasil pelatihan menunjukkan bahwa sebagai remaja siswa SMA memiliki pemahaman dasar tentang teknik fotografi sehingga mampu mengaplikasikan teknik table top studio untuk mengeksplorasi gaya hidup remaja dalam karya video dan foto.
\end{abstract}

Kata kunci: pelatihan, video, foto, table top studio, siswa SMA. 
PENDAHULUAN

Sebagai remaja, siswa SMA sangat dekat dengan penggunaan media video dan foto dalam kehidupan dan pergaulan sehari-hari. Remaja juga memiliki kedekatan dengan media sosial yang berbasis video dan foto. Melalui teknologi komunikasi berbasis video, foto dan aplikasinya, siswa memiliki kebiasaan memproduksi konten untuk pengisi media sosial atau untuk mendukung kegiatan kokurikuler dan ekstra kurikuler di sekolah. Hanya saja, potensi dasar ini perlu didukung dengan kemampuan teknik yang lebih baik dan perlu memberikan pengetahuan nilai estetikanya.

Pelatihan merupakan cara untuk mentransfer pengetahuan dan ketrampilan. Cara ini bukan memberikan atau mengajarkan sebuah teknik dari nol, melainkan suatu pengayaan pengetahuan. Peserta diasumsikan memiliki pengetahuan dasar tentang media video dan foto beserta karya videografi dan fotografi beserta fungsi praktis dalam kehidupan atau pergaulan peserta pelatihan. Latihan yang diikuti oleh peserta meliputi prinsip dasar media video, foto, cara mempresentasikannya sebagai karya seni dan untuk kegunaan dalam kehidupan keseharian bagi siswa untuk mendukung kurikuler di sekolah.

Video bagi siswa atau remaja saat ini merupakan bahan untuk konten dalam berbagai media sosial, pengisi blog, atau media ekspresi untuk media sosial. Dalam hal ini, tentu teknik dan teknologi yang digunakan adalah yang simpel dan bersifat instan. Remaja dapat memanfaatkan video untuk mengkomunikasikan ide-idenya untuk diunggah melalui media sosial. Sebagian remaja masa kini mengisi blog dengan video sederhana. Konten yang dibuat umumnya bersifat informatif mengenai peristiwa di sekitar sekolah. Untuk itu, melalui pelatihaninidibuat isian berupa tutorial yang berhubungan dengan kebutuhan pelajar.

Foto dan video diproduksi menggunakan perangkat yang sama, yaitu kamera. Saat ini, sebuah perangkat pembuat foto umumnya juga sekaligus dapat digunakan untuk membuat video. Bagi para siswa SMA foto umumnya lebih sering digunakan untuk berbagai pengisi konten sosial media, pendukung visual pada majalah 
dinding dan dokumentasi. Kebanyakan foto juga dibuat dengan peralatan fotografi sehari-hari seperti smartphone.

Table top studio pada prinsipnya adalah sebuah studio untuk membuat gambar foto dan video yang dibuat dalam skala lebih kecil. Prinsip dasar dari table top studio adalah memindahkan kesan ruang tanpa batas pada studio ke dalam ukuran yang lebih kecil, yang dapat diletakkan di atas meja. Teknik ini umumnya digunakan untuk membuat foto dan video produk. Konsep pokok table top studio adalah membuat kesan bahwa benda yang ada di atasnya tidak dapat diidentifikasi diletakkan atau diambil gambarnya di mana, atau lokasi pembuatan gambarnya tidak dapat dikenali. Fokus hasil gambar akan terkonsentrasi pada benda-bendanya dan latar belakng tidak menggangu konsentrasi orang yang menikmatinya.

Peserta pelatihan adalah siswa SMA Negeri 1 Padangpanjang. Siswasiswa kelas XI mendapat prioritas penawaran dari pihak sekolah melalui bidang kesiswaan. Program pelatihan video dan foto dengan menggunakan table top studio menyasar peserta pemula usia remaja. Sebagai siswa, video dan foto adalah praktik ilmu pengetahuan alam utamanya ilmu fisika tentang optik, cahaya, jarak dan kecepatan. Sebagai remaja, video dan foto sangat terbuka baik dalam sisi penggalian ide, pengembangan teknik dan cara mengekspresikannya.

\section{METODE}

Pelatihan dilaksanakan dengan metode praktik membuat foto dan video untuk kepentingan yang berbeda. Video dipersiapkan untuk mengisi konten media sosial dan video blog (vlog), sedangkan foto dipersiapkan untuk mengisi konten majalah dinding sekolah. Praktik dilakukan dengan memberikan dasar-dasar pengetahuan tentang videografi dan fotografi, disertai dengan diskusi tentang penggalian ide-ide utama yang dapat diekspresikan melaui teknik table top studio.

Prinsip dasar mengenai table top studio adalah membuat kesan ruang tanpa batas melalui alat-alat yang dibentuk sedemikian rupa menyerupai sebuah studio berukuran kecil yang dapat diletakkan di atas meja. Siswa diajarkan untuk membuat table top 
studio berdasarkan keperluan untuk melaksanakan ide masing-masing. Untuk memenuhi prinsip kontras pada hasil gambar, maka peserta dapat memilih untuk membuat table top studio berwarna hitam untuk objek yang cenderung berwarna terang, atau berwarna putih untuk objek yang cenderung berwarna gelap.

Aplikasi dari pembuatan video dan foto dilakukan secara bersamaan dalam satu set table top studio. Artinya, sebuah set dapat digunakan untuk membuat video tentang sebuah ide tertentu, kemudian dibuat pula dalam versi foto. Sebuah ide dapat dieksekusi secara berkelompok atau dikerjakan sendiri-sendiri oleh peserta. Bila video dan foto memerlukan proses editing dan penyempurnaan, maka dilakukan menggunakan aplikasi foto dan video pada smartphone. Hasil praktik disepakati sebagai hasil karya bersama atas nama sekolah.

Luaran pelatihan merupakan karya foto dan karya video berdurasi pendek. Luaran pelatihan berupa foto dicetak dan dipamerkan sebagai pengisi rubrik pada majalah dinding sekolah. Ukuran, jumlah, jenis bahan, dan tema foto disesuaikan dengan ketersediaan ruang pada majalah dinding sekolah edisi berjalan,sedangkan hasil video ditampilkan sebagai bahan pengisi sosial media dan konten untuk video blog. Video ditampilkan pada akun milik masing-masing peserta.

\section{HASIL YANG DICAPAI}

Bagi siswa SMA memiliki kegiatan ekstra kurikuler seni visual merupakan hal yang menggembirakan. Hal ini tentu merupakan indikasi baik, karena secara khusus siwa-siswi yang memiliki minat khusus pada seni video atau foto berperan secara aktif. Diselenggarakannya pendampingan bidang seni merupakan ajang kreativitas bagi kalangan siswa dan remaja. Umumnya, remaja adalah pelaku aktif pembuat toto atau video dalam aktivitas sehari-hari, utamanya melalui perangkat gadged seperti smartphone.

Remaja umumnya memilih media yang terintegrasi secara global dengan jaringan internet. Selain itu, juga mereferensi karya seni sejenis melalui jejaring sosial media yang berbasis visual seperti Instagram. Kondisi ini memberikan manfaat 
dalam praktik dan berekspresi bagi siswa. Pelatihan pembuatan video dan foto makro menggunakan table-top studio bagi siswa SMA memberi pengayaan nilai estetika. Siswa belajar memperkaya pengetahuan estetika visual untuk karya videografi dan fotografi dari sisi tema, teknik dan eksperimen-eksperimen.

\section{Table} top studio mengaplikasikan teknik makro, yaitu teknik memvisualisasikan benda dalam jarak dekat dengan lensa fokal pendek, sehingga diperoleh hasil foto yang detail, tampak besar dan jelas. Peserta pelatihan wajib memiliki pengaturan sudut pengambilan gambar yang dekat pada objek. Teknik ini sekaligus akan menghasilkan efek visual yang diperoleh dari pemilihan lensa yang menghasilkan ruang tajam (bokeh); ruang tajam pada objek dipilih untuk difokuskan pada titik yang diutamakan.

Hasil yang dikehendaki pada teknik table top studio menuntut spesifikasi teknik yang bisa diperoleh melalui kamera SLR (single lens reflect). Maka sebagai pengantar diberikan dasar-dasar mengenai fotografi dengan kamera SLR beserta penggunaan lensa fokal pendek. Dalam praktik, diberikan pula teknik mengatur objek, membuat komposisi gambar, dan teknik pencahayaan. Pada aspek estetika diberikan pengetahuan mengenai kesan, bidang, garis, titik, dan warna.

Capaian pengetahuan dasar tentang videografi dan fotografi bisa dipahami secara baik. Siswa tertantang mengaplikasikan dan mengintegrasikan mata pelajaran ilmu pengetahuan alam utamanya ilmu fisika. Prinsip dasar fisika untuk video dan foto adalah mengenai optik, cahaya, waktu, jarak, dan kecepatan, sedangkan prinsipprinsip estetika diperoleh dari eksperimen tentang pencahayaan, warna serta pemilihan dan pengaturan komposisi objek yang divisualisasikan.

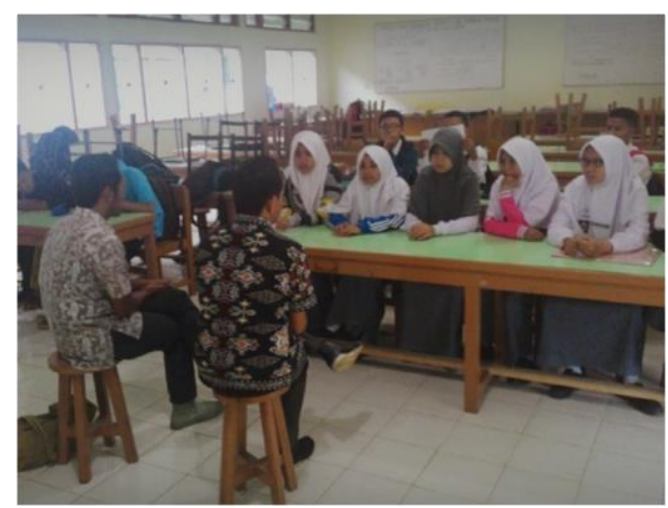

\section{Gambar 1.}

Peserta pelatihan

Foto: Choiru Pradhono (2016) 


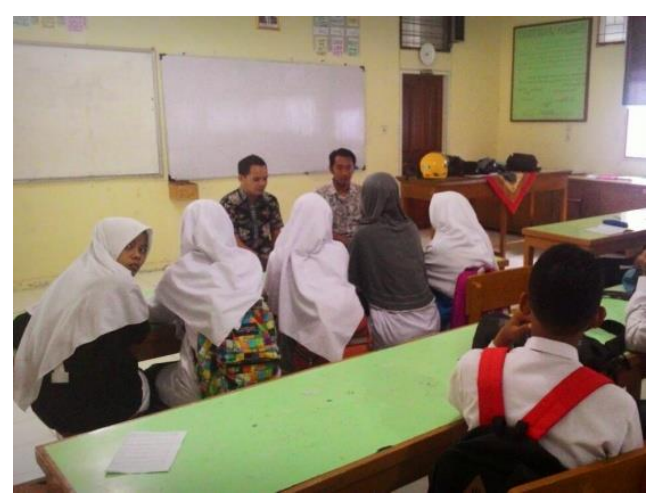

Gambar 2.

Penjelasan materi pelatihan.

(Foto: Choiru Pradhono, 2016)

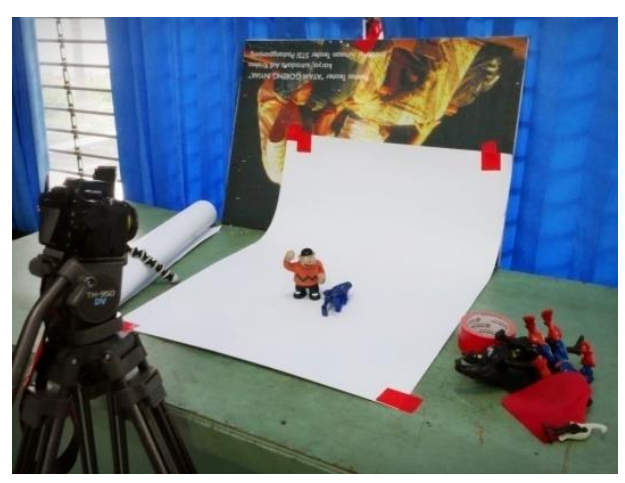

Gambar 3.

Alat dan bahan

(Foto: Yatno Karyadi, 2016)

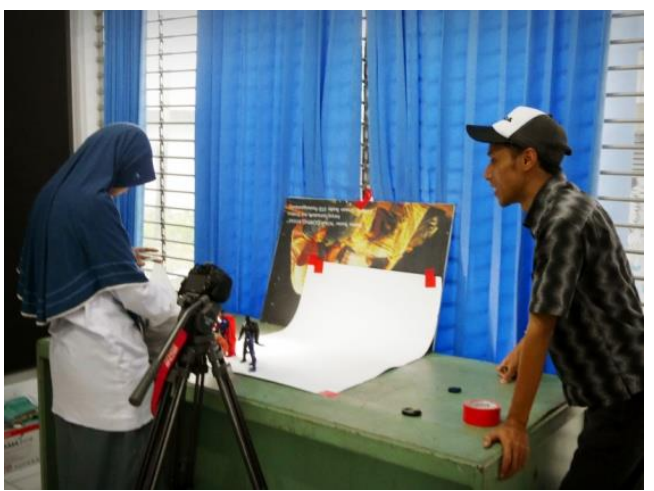

Gambar 4.

Proses pelatihan.

(Foto: Bari Rahmat, 2016)

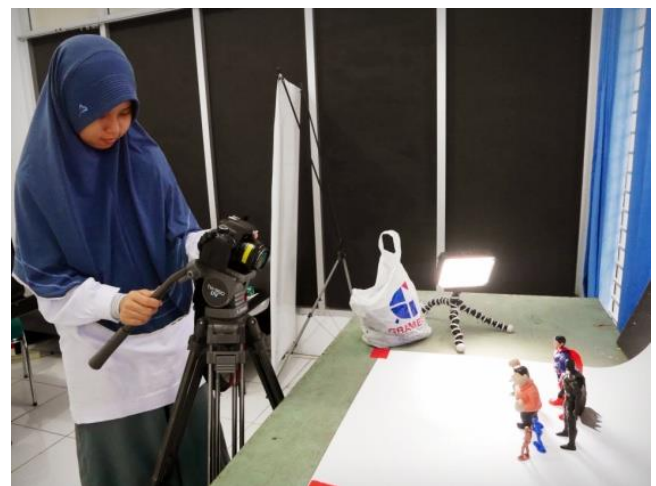

Gambar 5.

Praktik peserta.

(Foto: Bari Rahmat, 2016)

Pelatihan video dan foto dengan teknik table top studio menghasilkan dua buah karya video dan empat karya foto dengan tema gaya hidup remaja. Ide pokok dalam setiap karya diperoleh dan dikembangkan oleh peserta pelatihan pada setiap pertemuan. Karya video dirancang dalam durasi pendek, berisi tentang tips-tips ringan untuk sesama pelajar. Karya foto umumnya menggambarkan tentang ekspresi diri melalui benda-benda kesayangan masing-masing. Berikut adalah karya video dan foto hasil pelatihan: 


\section{Karya Video "Tips Meraut Pensil" (15 detik)}

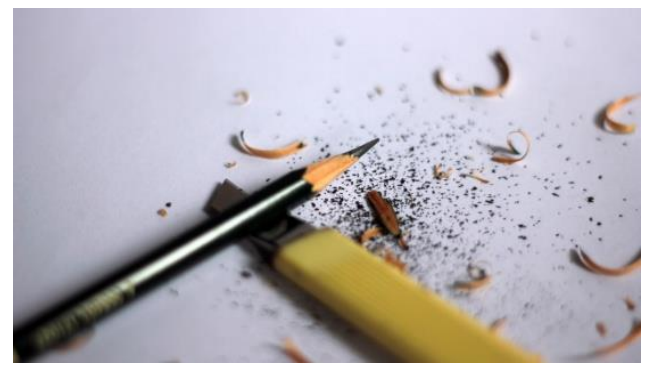

Gambar 6.

Tips meraut pensil.

(Capture image: Chahaya Fortuna, 2016)

Merupakan video tutorial cara meraut pensil menggunakan pisau. Ide pokoknya adalah bahwa dengan menggunakan pisau cutter saja, dapat menghasilkan pensil untuk menulis atau mengambar senyaman pensil yang diruncingkan menggunakan rautan. Video ini berdurasi 15 detik, terdiri dari empat shot yang menuntun urutan meruncingkan pensil agar nyaman digunakan. Gagasan tersebut muncul karena peserta merasa penting untuk tidak menggantungkan pada peralatan tertentu, tetapi kreativitas agar kebutuhan belajar dapat terpenuhi.
2. Karya Video "Bekal Maksi" (15 detik)

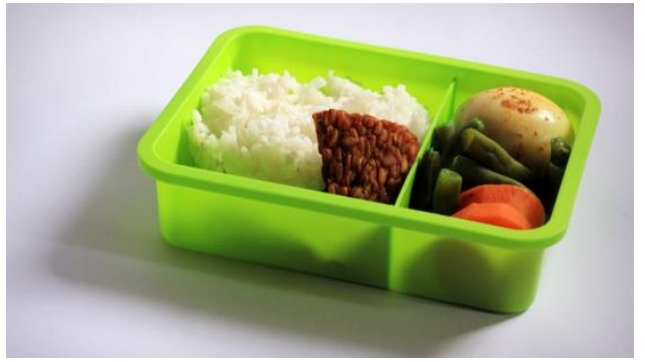

\section{Gambar 7.}

Bekal Maksi.

(Capture image: Chahaya Fortuna, 2016)

"Bekal Maksi" adalah video yang menggambarkan tentang bagaimana menyiapkan makan siang yang praktis bagi siswa yang memiliki aktivitas yang padat. Siswa SMA memiliki berbagai kegiatan di luar jam pelajaran, sehingga kebanyakan tidak sempat untuk pulang atau membeli makan di luar sekolah. Ide dasarnya adalah tentang kegiatan sehari-hari siswa sekolah, saat makan siang tidak boleh terlewatkan waktu, karena banyaknya agenda kegiatan. Siswa memerlukan banyak energi dan gizi yang seimbang untuk menjalani aktivitas harian. Video ini berdurasi 20 detik dan terdiri dari lima shot. 
3. Karya Foto "The Toys"

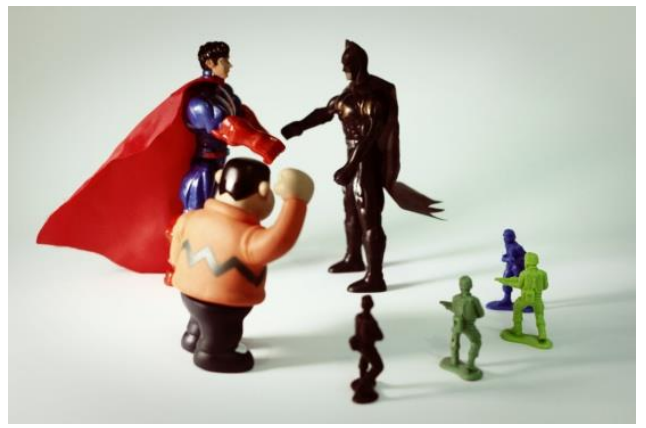

Gambar 8.

The toys.

(Foto: Chahaya Fortuna, 2016)
4. Karya Foto "Pernik"

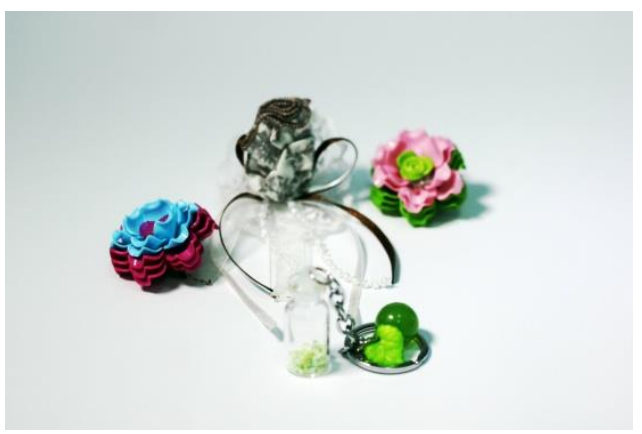

Gambar 9.

Pernik.

(Foto: Chahaya Fortuna, 2016)

Objek foto adalah beberapa aksesoris yang biasa dikenakan oleh siswa perempuan. Peserta memilih mengambil objek berupa bros dan gantungan kunci. Foto ini merupakan gambaran gaya hidup bagi kebanyakan remaja putri. Kesan yang ingin diungkap adalah menunjukkan sifat feminim, cantik, dan lembut melalui barang-barang kesukaan yang dekat dengan kehidupan sehari-hari.

\section{Karya Foto "Tentang Waktu"}

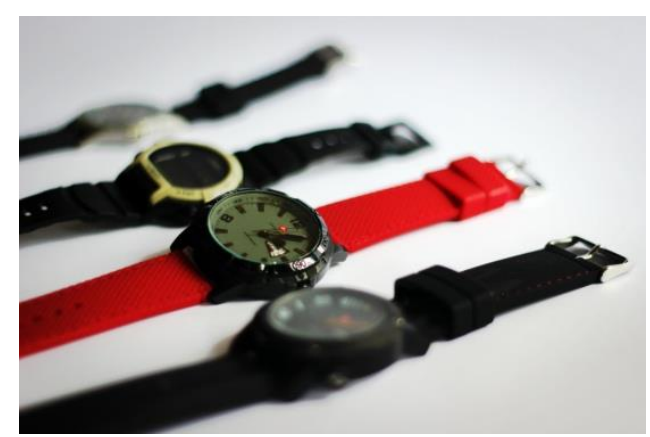

Gambar 10.

Tentang waktu.

(Foto: Flori Fatiannisa, 2016) 
Objek foto berupa beberapa jam tangan yang ditata dengan komposisi diagonal. Teknik yang diutamakan adalah membuat point of interest dengan fokus pada warna yang dominan. Cara ini menunjukkan salah satu teknik untuk membuat sebuah oyek lebih menonjol dibanding objek lainnya. Komposisi disesuaikan dengan sudut pengambilan gambar terhadap objek-objek yang cenderung setipe. Fokus lensa diarahkan pada objek yang ditonjolkan agar menjadi pusat perhatian.

\section{Karya Foto "My Stuff"}

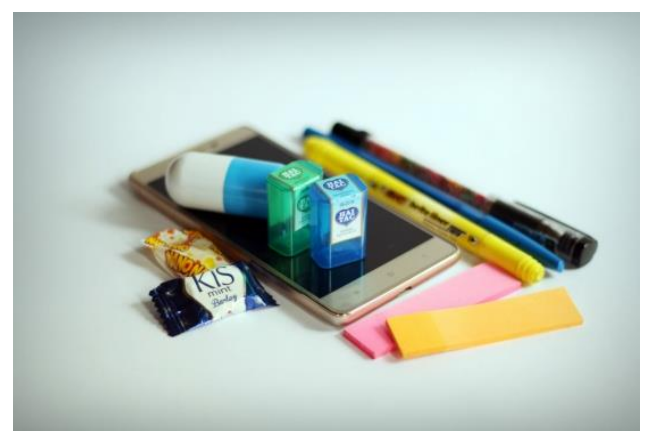

Gambar 11.

My Stuff.

(Foto: Flori Fatiannisa, 2016)

Objek dalam foto ini berupa barang-barang harian seorang pelajar, seperti smartphone, pena, highlighter, label pembatas buku, dan beberapa buah permen. Gambaran gaya hidup pelajar masa kini tercermin dari pemilihan jenis barang, pilihan warna serta bentuknya. Benda-benda tersebut memberi kesan keceriaan bagi remaja. Warna-warna dikomposisikan untuk mengesankan sesuatu yang dinamis.

Dari hasil pelatihan tersebut tujuan untuk mengaitkan ilmu pengetahuan alam dan seni dalam bentuk video dan foto terbukti cukup efektif. Siswa mampu memahami aspek-aspek estetika seperti tata letak, komposisi, keseimbangan, dan warna. Pembuatan video dan foto makro menggunakan tabletop studio merupakan simulasi teknik studio yang disederhanakan. Bagi para siswa hal ini menjadi menarik karena secara praktis dapat menjadi media belajar dan juga media berekspresi.

Mengenai gaya hidup remaja dalam karya video dan karya foto, pada kenyataannya remaja umumnya cenderung memilih media ekspresi yang populer dan praktis. Media ekspresi ini umumnya diakses melalui gadget seperti smartphone. Dengan menguasai teknik table top studio, maka pengalaman estetis para siswa menjadi bertambah dalam menghasilkan karya video dan foto 
yang lebih menarik, sekalipun untuk diekspresikan melalui gadget.

Dengan menggunakan table top studio memuat pula teknik makro yaitu teknik memvisualisasikan benda dalam jarak dekat, sehingga diperoleh hasil foto yang detail, tampak besar dan jelas (Hoddinott, 2011). Pengertian makro hampir sama dengan close-up, tetapi memiliki pengaturan sudut pengambilan gambar yang lebih dekat lagi. Teknik ini menghasilkan kesan bokeh yang dihasilkan dari pemilihan lensa, ruang tajam pada objek difokuskan pada satu titik yang diutamakan.

Para siswa telah memvisualisasikan still-life, yakni peristiwa membuat gambar dari objekobjek mati dan benda-benda yang tidak bergerak dengan teknik makro dan close-up (Best, 2010). Dalam memvisualisasikan benda-benda, si pembuat visuallah yang menata bendabenda, sehingga memiliki paduan komposisi, garis, bentuk dan warna yang menarik. Teknik ini umumnya digunakan untuk memvisualisasikan barang-barang pribadi atau foto dan video produk.
Table top studio yang berbentuk bidang lengkung digunakan untuk meletakkan objek, sehingga menimbulkan kesan tanpa batas. Fungsinya adalah untuk meniadakan sudut yang mengesankan bahwa benda-benda yang ada di atasnya berada dalam sebuah ruang yang tidak dapat diidentifikasi keberadaan dan waktu kejadiannya. Hal ini akan mengabaikan background, sehingga fokus perhatian tertuju pada bendanya (Harnischmascher, 2012). Tabletop dapat dibuat dengan bahan-bahan sederhana seperti kertas karton atau kain.

Aplikasi dari teknik table top studio terbukti mampu menimbulkan ide-ide dengan memanfaatkan barang atau benda-benda yang ada di sekitar. Dengan mengaplikasikan teknik komposisi, pencahayaan dan ruang tajam, diperoleh efek visual yang estetis. Estetika dalam bidang visual berarti bahwa bila suatu benda menimbulkan rasa keindahan di luar fungsi asli dari kebendaan tersebut (Sumarjo, 2010). 


\section{KESIMPULAN}

Hasil pelatihan menyatakan bahwa pada umumnya siswa SMA memiliki ketertarikan pada bidang fotografi atau videografi. Sebagai remaja, para siswa umumnya juga dapat memilih dan menentukan sendiri media ekspresi untuk memamerkan karya fotografi dan karya videonya.Teknik table top studio merupakan salah satu teknik sebagai bekal pengetahuan fotografi bagi siswa dari sisi pemilihan angle dan komposisi serta ide dasar dalam pembuatan gambar foto atau video. Ide-ide dasar dalam membuat foto ekspresi rata-rata digali dengan merujuk pada referensi yang bersifat populer seperti media sosial yang berbasis foto dan video.

Perlu pembekalan dasar-dasar dan prinsip fotografi untuk mempermudah logika pembuatan gambar foto ekspresi yang bernilai estetika bagi siswa dalam statusnya sebagai pelajar dan sebagai remaja.Untuk memacu kreativitas pada peserta remaja, dapat menggunakan peralatan dan bahan yang bisa diperoleh di sekitar, barang-barang pribadi peserta dan hal-hal yang populer dalam kehidupan sehari-hari.

\section{KEPUSTAKAAN}

Best, Kevin. (2010). Still Life Photography, New York: Elsevier.

Harnischmascher, Cyril (2012), Tabletop Photography, New York: Elsevier.

Hoddinott, Ross. (2011). Digital Macro Photography, New York: Elsevier.

Sumarjo, Jakob. (2010). Filsafat Seni, Bandung: Institut Teknologi Bandung Press. 
FILOSOFI "BATOBOH": Dalam masyarakat Minangkabau upacara-upacara yang dilakukan sebelum mendirikan bangunan baik Rumah Gadang maupun Balairung (Balai Adat) serta bangunan lainnya yang dikenal dengan beberapa upacara yang disebut dengan batoboh. Batoboh berasal dari kata Taboh yang artinya menebang atau mengambil sesuatu, jadi dengan mengambil kayu dihutan sebagai bahan utama dalam membangun rumah dan bangunan lainnya. Upacara Batoboh ini sangat bermanfaat bagi masyarakat Minangkabau yaitu dapat meningkatkan Gotong-Royong dan solidaritas antar sesama suku Minangkabau karena memberi kesempatan kepada kerabat-kerabat untuk terlibat dalam pembangunan rumah serta bangunan lain.

Alamat Redaksi: LPPMPP ISI Padangpanjang Jalan Bahder Johan Padangpanjang 27128 Sumatera Barat Telp. (0752) 485466, Fax.(0752) 82803 e-mail: batoboh@gmail.com

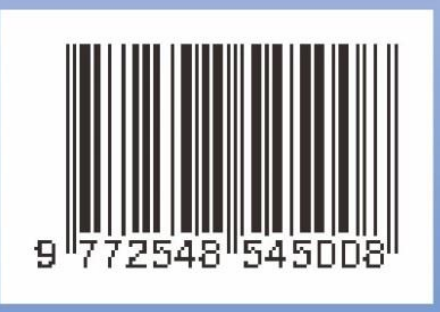

